RESEARCH REPORT

\title{
Partnership history and mental health over time
}

\author{
M Willitts, M Benzeval, S Stansfeld
}

J Epidemiol Community Health 2004;58:53-58

\begin{abstract}
Study objective: To describe the mental health of men and women with differing histories of partnership transitions.

Design: Data from nine waves of the British Household Panel Survey, a stratified general population sample, were used to calculate age standardised ratios and $95 \%$ confidence intervals for mean General Health Questionnaire scores for groups with different partnership transition histories.

Participants: 2127 men and 2303 women aged under 65 who provided full interviews at every survey wave.

Main results: Enduring first partnerships were associated with good mental health. Partnership splits were associated with poorer mental health, although the reformation of partnerships partially reversed this. Cohabiting was more beneficial to men's mental health, whereas marriage was more beneficial to women's mental health. The more recently a partnership split had occurred the greater the negative outcome for mental health. Women seemed more adversely affected by multiple partnership transitions and to take longer to recover from partnership splits than men. Single women had good mental health relative to other women but the same was not true for single men relative to other male partnership groups. Conclusions: Partnership was protective of mental health. Mental health was worse immediately after partnership splits, and the negative outcomes for health were longer lasting in women. Future work should consider other factors that may mediate, confound, or jointly determine the relation between partnership change and health.
\end{abstract}

See end of article for authors' affiliations .....................

Correspondence to: Michaela Benzeval, Department of Geography, Queen Mary, University of London, Mile End Road, London El 4NS, UK; m.benzeval@qmw.ac.uk

Accepted for publication 11 May 2003
$M$ arital status is well recognised as a key demographic variable associated with both mental and physical health. In general, being married seems to be protective of health, although more so for men than women. ${ }^{1}$ For example, people who are married have been shown to have longer life expectancy, lower death rates, lower self reported morbidity, and better psychological wellbeing than people who are unmarried. ${ }^{2}$ People who are separated and divorced display poorer health compared with people who are married, single and, often, to widowed people. ${ }^{3}$

However, most previous studies of marital status and health have been cross sectional and have not taken into account previous marital history or health. From these studies it is not clear whether the health or ill health associated with marital status is a consequence of that marital status or whether previous health might have influenced selection into a particular marital status. A longitudinal perspective on marital history and health may be helpful, therefore, in understanding the association between marital status and health, and the type of processes involved. It is also important to consider that multiple changes in marital status over the lifecourse may have an impact on health that cannot be easily identified from cross sectional data.

In addition, given the increase in cohabitation rates over the past few decades, it is necessary to broaden our notion of partnerships to include people who cohabit as well as those who marry. Past research has often included cohabiting people in an unmarried category ${ }^{4}$ or, increasingly, combined them with people who are married. ${ }^{5}$ However, some research has shown that people who cohabit are more likely to have poorer health than those who are married. ${ }^{4}$

Given the limited longitudinal analysis of partnerships change and health, little is known about the pattern of health changes over time associated with changes in partnership status. Booth and Amato $^{6}$ indicated a rise in stress before divorce, which later reduced. In another study, increased psychological distress associated with divorce was found to diminish over time, although it was seen to persist for some time beyond the initial separation. ${ }^{7}$ Furthermore, the health differential between people who are married and those who are divorced lasted longer in women. ${ }^{7}$

The ability of new relationships to overcome the negative effects on health of previous failed relationships or the number of marital transitions from which a person can recover is less clear. Studies have tended to group people who remarried in with those that remain divorced, ${ }^{8}$ which essentially ignores entry into a second partnership and its potential benefits for health.

Against this background, the aim of this paper is to describe the association between people's partnership histories and their mental health over time. More specifically, it addresses three key questions.

- What is the effect of multiple partnership transitions on male and female mental health?

- Do the effects on mental health differ for people who marry compared with those that cohabit?

- Does the time since a partnership transition change the consequences for mental health?

We expect that all of the associations investigated will vary by gender, and all analyses are conducted separately to explore this.

\section{METHODS}

The aim of this paper is to explore the association between changes in partnership status over a person's lifetime and their mental health. Given the very different patterns of partnership change under and over the age of 65 (when the latter mainly consists of widowhood), this paper concentrates on the relationship for people under 65 years. The best dataset for this purpose is the British Household Panel Survey (BHPS). 


\section{BHPS dataset}

The BHPS was begun in 1991 and this paper is based on information for the first nine waves of the survey (199199/00). ${ }^{9}$ The initial sample was designed as a nationally representative sample of private households in Great Britain and covered about 5000 households and 10000 adults. (For more information on the sampling strategy see Taylor $\left.{ }^{10}\right)$. All adults are interviewed annually. This paper focuses on 4430 individuals under the age of 65 in wave 9 who have given full interviews, and have provided complete partnership information, in every year of the survey. Strenuous efforts have been made to follow up all of the initial members of the panel over time and the survey has achieved year on year response rates of about $95 \%$. Nevertheless by wave 7 , for example, only $76 \%$ remained in the sample. ${ }^{11}$ Longitudinal weights have been calculated to correct for biases in the original respondents, and subsequent attrition, and are used in this paper. ${ }^{10}{ }^{12}$

\section{Health questions}

This paper focuses on the 12-item general health questionnaire (GHQ), which is a well validated screening instrument for psychological distress, largely depression and anxiety. ${ }^{13}$ Each of the 12 items has four possible responses. Endorsement of either of the two most extreme responses, for example, "more than usual" or "much more than usual" as compared with "same as usual" or "not more than usual" elicits a score of 1 with a total score ranging from 0 to 12 . Mean GHQ scores have been used to create standardised ratios (see below), which are used throughout this paper. It needs to be borne in mind that the 12 -item GHQ is a comparatively crude screening instrument for psychological distress that does not discriminate between depression and anxiety, and is susceptible to high levels of false positives when compared with interview measures of mental ill health. ${ }^{13} 14$

\section{Partnership change}

The BHPS asks respondents for confirmation of their partnership status and information on any changes in each annual interview. In addition, in wave 2 all respondents were asked for a complete lifetime marital and cohabiting history. From this information, the number of partnership formations (first or otherwise) and partnership splits that each individual has experienced has been identified. Cohabiting or marrying are treated in the same way. In principle, this means that same sex couples would be included in this analysis, in practice, none are present in the survey for all nine waves, and so this study is based on heterosexual partnerships.

Many couples cohabit then marry each other, or separate before they divorce; in both of these circumstances we have treated the connected changes as a single transition, with the initial cohabitation and separation respectively treated as the key stages in terms of exploring the effect of the transition on a person's mental health. (Hope and colleagues ${ }^{7}$ adopt a similar approach). However, we do recognise that the subsequent marriage and divorce may have additional effects on health. For simplicity we have not investigated these here, but plan to do so in future dynamic analyses of this dataset.

Nine per cent of the sample has been single throughout their lives. Over half of both men and women in the sample have experienced only one positive transition (that is, started a cohabitation or marriage that is ongoing) during their lifecourse. Thirty five per cent of respondents have experienced at least one partnership split during their lifecourse up to the end of the survey period. Nearly a third of people who have separated from their first partnership are currently alone after the break up, while $70 \%$ of them ( $25 \%$ of survey) have remarried or begun another cohabitation. Of these people, a small number have gone on to have several further partnerships, although most remain in their second partnership.

\section{Statistical methods}

To explore the mental health consequences of partnership transitions, standardised ratios for the mean scores of GHQ have been calculated for men and women separately using the indirect method. ${ }^{15}$ Age specific mean GHQ scores from the whole sample were applied to each partnership group to create an expected score based on their age distribution. This is then compared with the actual mean score for the partnership group to give the standardised mean GHQ ratio (Similar to the standardised mortality ratio). Partnership groups with ratios greater than 100 have a higher mean GHQ score than would be expected given their age distribution and those groups with less than 100 have a lower score than would be expected. Age standardisation ensures that any observed differences are not the result of the different age structures of the various partnership groups. However, as the ratios have been calculated separately for men and women, strictly speaking, comparisons between them cannot be made. Confidence intervals have been calculated at the $95 \%$ level to assess whether the mental health differences observed are attributable to chance. ${ }^{16}$

\section{RESULTS}

The results for these initial analyses of the BHPS in relation to the three research questions above are presented below.

\section{What is the effect of multiple partnership transitions on male and female mental health?}

Table 1 shows the relative mental health status at wave 9 of the different partnership transition groups by gender. Men who experienced one partnership split in their lifetime had significantly poorer mental health than those who had not experienced any transitions, and than men who had formed a first partnership. Oddly, the best mental health was observed in men who had undergone two or more partnership reformations, and this was significantly better than all other men.

Women who had not experienced any partnership transitions or who had formed and remained in their first partnership had significantly better mental health than those who had experienced partnership splits. This was irrespective of the number of splits encountered and whether or not a partnership reformation had occurred. However, the mental health of women became worse as the number of partnership splits rose or similarly as the number of partnership reformations increased. The poorest mental health was among those women who had experienced multiple partnership splits.

For both men and women it can be clearly seen that remarriage or re-cohabiting improved mental health as compared to remaining alone after a partnership split. However, for women, the ability of partnership reformation to overcome the negative mental health outcomes associated with partnership splits reduced in accordance with the number of splits already encountered.

\section{Do the effects on mental health differ for people who marry compared with those that cohabit?}

Table 2 shows final mental health status according to lifetime partnership history and current status. Men and women who formed a lasting first partnership actually differed in mental health according to whether they were married or cohabiting. Men with a cohabiting first partnership had significantly better mental health than those who married in their first partnership. In contrast, women who married had better 


\begin{tabular}{|c|c|c|c|c|c|c|}
\hline & $\begin{array}{l}\text { No partnership } \\
\text { transitions }\end{array}$ & $\begin{array}{l}\text { First } \\
\text { partnership }\end{array}$ & $\begin{array}{l}\text { First } \\
\text { partnership split }\end{array}$ & $\begin{array}{l}\text { First } \\
\text { partnership } \\
\text { reformation }\end{array}$ & $\begin{array}{l}\text { Multiple } \\
\text { partnership } \\
\text { splits }\end{array}$ & $\begin{array}{l}\text { Multiple } \\
\text { partnership } \\
\text { reformations }\end{array}$ \\
\hline \multicolumn{7}{|l|}{ Male } \\
\hline $\begin{array}{l}\text { Point } \\
\text { estimate }\end{array}$ & 101.6 & 96.2 & 128.7 & 105.4 & 115.1 & 74.1 \\
\hline Lower $\mathrm{Cl}$ & 91.5 & 91.8 & 115.0 & 96.1 & 93.9 & 62.1 \\
\hline Upper Cl & 112.4 & 100.7 & 143.7 & 115.4 & 139.6 & 87.7 \\
\hline $\begin{array}{l}\text { Number } \\
\text { Female }\end{array}$ & 256 & 1243 & 165 & 287 & 58 & 118 \\
\hline $\begin{array}{l}\text { Point } \\
\text { estimate }\end{array}$ & 81.2 & 81.6 & 137.7 & 109.4 & 153.5 & 132.2 \\
\hline Lower $\mathrm{Cl}$ & 71.4 & 78.2 & 128.6 & 102.2 & 139.9 & 117.9 \\
\hline Upper Cl & 91.9 & 85.2 & 147.3 & 116.9 & 168.0 & 147.9 \\
\hline Number & 150 & 1242 & 288 & 370 & 144 & 109 \\
\hline
\end{tabular}

mental health than those who cohabited at first partnership (albeit not significant).

Men who split from a partnership have poorer mental health than other men. This was particularly true of those who returned to a marital status of single after their last cohabit spell had ended who had significantly worse mental health than all other men. Men who cohabited after a partnership split had significantly better mental health than those who married and all other men who remained alone after a partnership split.

Women who married and remained so or who remained single throughout their lifetime displayed significantly better levels of mental health than those who had encountered partnership split(s) or partnership reformation(s). Those who had split from their partnerships and remained alone, especially if they had previously been married, experienced the poorest mental health. Such women had statistically significantly worse mental health than all other groups except those alone after a separation from one cohabit spell. For women who had experienced partnership splits during their lifecourse, those who reformed partnerships (marriage or cohabiting) had significantly better mental health than those who remained alone.

Does the time since a partnership transition change the consequences for mental health?

Table 3 shows the relative mental health of men and women by the length of time since their last partnership transition occurred. Women who formed a first partnership less than five years ago had better mental health than all other women, such women had statistically significant better mental health than those who had experienced partnership split(s) or partnership reformation(s). However, men who formed a first partnership less than five years ago only had significantly better mental health than men who had encountered a partnership split less than five years ago.

Men who had undergone a partnership split over 10 years ago had significantly better mental health than those whose separation had occurred less than 10 years ago. In contrast, women's mental health did not seem to recover from their last partnership split, irrespective of the length of time since it occurred. Although, women who had encountered a partnership split most recently (five or less years ago) displayed significantly worse mental health than women who had experienced a partnership split less recently ( six to ten years ago).

Men who reformed partnerships less than five years ago also had significantly better mental health than those who underwent a partnership split less than five years ago. Only women who reformed partnerships over six years ago had significantly better mental health than women who experienced a partnership split less than five years ago.

\section{DISCUSSION}

The analysis presented in this paper has begun to explore the association between partnership change and mental health.

\begin{tabular}{|c|c|c|c|c|c|c|c|}
\hline \multirow{2}{*}{$\begin{array}{l}\begin{array}{l}\text { Partnership } \\
\text { history }\end{array} \\
\begin{array}{l}\text { Final } \\
\text { partnership } \\
\text { status }\end{array}\end{array}$} & \multirow{2}{*}{$\begin{array}{l}\begin{array}{l}\text { No } \\
\text { partnership } \\
\text { transitions }\end{array} \\
\text { Single }\end{array}$} & \multicolumn{2}{|c|}{ First partnership } & \multicolumn{2}{|c|}{$\begin{array}{l}\text { First or multiple } \\
\text { partnership splits }\end{array}$} & \multicolumn{2}{|c|}{$\begin{array}{l}\text { First or multiple partnership } \\
\text { reformations }\end{array}$} \\
\hline & & Married & Cohabiting & $\begin{array}{l}\text { Divorced, } \\
\text { widowed, or } \\
\text { separated }\end{array}$ & Single & Married & Cohabiting \\
\hline \multicolumn{8}{|l|}{ Male } \\
\hline Point estimate & 101.6 & 98.4 & 78.6 & 112.7 & 149.5 & 99.9 & 90.3 \\
\hline Lower $\mathrm{Cl}$ & 91.5 & 93.8 & 65.8 & 99.2 & 128.0 & 90.2 & 78.6 \\
\hline Upper Cl & 112.4 & 103.2 & 93.2 & 127.6 & 173.6 & 110.3 & 103.3 \\
\hline $\begin{array}{l}\text { Number } \\
\text { Female }\end{array}$ & 256 & 1121 & 122 & 141 & 82 & 249 & 155 \\
\hline Point estimate & 81.2 & 80.9 & 92.6 & 146.1 & 133.4 & 112.1 & 120.6 \\
\hline Lower $\mathrm{Cl}$ & 71.4 & 77.3 & 79.4 & 137.4 & 117.7 & 104.6 & 108.4 \\
\hline Upper Cl & 91.9 & 84.5 & 107.3 & 155.2 & 150.5 & 120.1 & 133.7 \\
\hline Number & 150 & 1149 & 94 & 337 & 95 & 339 & 140 \\
\hline
\end{tabular}


Table 3 Age standardised ratios for mean GHQ and 95\% confidence intervals for people less than 65 years for time (in years) since last partnership transition by gender

\begin{tabular}{|c|c|c|c|c|c|c|c|c|c|c|c|c|}
\hline & \multirow[b]{2}{*}{$\begin{array}{l}\text { No partnership } \\
\text { transitions }\end{array}$} & \multicolumn{4}{|c|}{ First partnership } & \multicolumn{3}{|c|}{ Partnership split } & \multicolumn{4}{|c|}{ Partnership reformation } \\
\hline & & $\begin{array}{l}1-5 \\
\text { years ago }\end{array}$ & $\begin{array}{l}6-10 \\
\text { years ago }\end{array}$ & $\begin{array}{l}11-15 \\
\text { years ago }\end{array}$ & $\begin{array}{l}\text { Over } 15 \\
\text { years } \\
\text { ago }\end{array}$ & $\begin{array}{l}1-5 \\
\text { years ago }\end{array}$ & $\begin{array}{l}6-10 \\
\text { years ago }\end{array}$ & $\begin{array}{l}\text { Over } 10 \\
\text { years } \\
\text { ago }\end{array}$ & $\begin{array}{l}1-5 \\
\text { years ago }\end{array}$ & $\begin{array}{l}6-10 \\
\text { years ago }\end{array}$ & $\begin{array}{l}11-15 \\
\text { years ago }\end{array}$ & $\begin{array}{l}\text { Over } 15 \\
\text { years ago }\end{array}$ \\
\hline \multicolumn{13}{|l|}{ Male } \\
\hline $\begin{array}{l}\text { Point } \\
\text { estimate }\end{array}$ & 101.67 & 89.31 & 98.6 & 73.45 & 103.94 & 142.82 & 126.12 & 77.91 & 95.79 & 78.18 & 137.82 & 81.97 \\
\hline Lower Cl & 91.58 & 77.07 & 83.82 & 64.21 & 98.21 & 125.73 & 101.31 & 59.49 & 83.89 & 62.48 & 117.28 & 68.13 \\
\hline Upper Cl & 122.69 & 109.33 & 119.75 & 91.57 & 124.95 & 167.85 & 150.73 & 97.73 & 116.4 & 97.57 & 162.77 & 101.46 \\
\hline $\begin{array}{l}\text { Number } \\
\text { Female }\end{array}$ & 254 & 156 & 112 & 205 & 741 & 120 & 46 & 49 & 162 & 70 & 73 & 94 \\
\hline $\begin{array}{l}\text { Point } \\
\text { estimate }\end{array}$ & 81.15 & 64.42 & 82.87 & 75.16 & 85.60 & 162.34 & 122.30 & 133.94 & 130.27 & 111.52 & 101.96 & 102.04 \\
\hline Lower Cl & 71.41 & 54.34 & 72 & 67.04 & 81.31 & 150.11 & 108.51 & 119.96 & 118.98 & 98.27 & 87.19 & 89.98 \\
\hline Upper Cl & 100.14 & 81.64 & 102.13 & 93.38 & 104.74 & 188.54 & 145.41 & 158.03 & 153.89 & 133.67 & 123.41 & 123.24 \\
\hline Number & 150 & 112 & 124 & 197 & 802 & 190 & 108 & 116 & 178 & 108 & 76 & 117 \\
\hline
\end{tabular}

It provides novel research on the longitudinal association between different types of partnerships (marriage or cohabitation), partnership transitions, and mental heath. In the main, the results are broadly consistent with the limited literature that exists.

The finding that the number of prior marital splits moderated the health enhancing effects of subsequent partnerships, with multiple marriages being associated with poorer mental health is supported by a study by Barrett. ${ }^{17}$ This suggests that although a new partnership improves health, it cannot entirely eliminate the detrimental effect of a previous separation..$^{18}$ However, the possibility of prior mental ill health or relationship difficulties increasing the risk of subsequent relationship breakdown cannot be ruled out.

In this study, as in some others, the negative health effects of a partnership split was greater for women than for men. ${ }^{8}{ }^{19}$ However, this is not true of all studies. For example, Maciejewski and colleagues ${ }^{20}$ found no gender differences in depression following the death of a spouse, divorce, or partnership problems. Our study also shows that forming a second or subsequent partnership has a less beneficial effect

\section{Key points}

- Enduring first partnerships were associated with good mental health. Partnership splits were associated with poorer mental health, although the reformation of partnerships partially reversed this. The more recently a partnership split had occurred the greater the negative outcome for mental health.

- Cohabiting was more beneficial to men's mental health, whereas marriage was more beneficial to women's mental health.

- Women were more adversely affected by multiple partnership transitions and seemed to take longer to recover from partnership splits than men.

- Women who remained single throughout the lifecourse displayed good levels of mental health relative to other women, but this was not the case for single men.

- Further research is required to explore the explanations for these complex associations between partnership and health, in particular the role of children in the household, financial resources, and employment would seem crucial. on women's health than men's, and that women were more adversely affected by multiple partnership transitions and that the effects were longer lasting. This result is supported by a meta analysis of studies of physiological changes after marital conflict, which found the detrimental effects showed greater persistence for women than for men. ${ }^{21}$

Men in first partnerships displayed better mental health than those who remained single, whereas women who remained single displayed equally good mental health to those in their first partnership and better health than those who had experienced a partnership split. This is further support for the finding that single men display more distress than married men and vice versa for women. ${ }^{122}$ Goldman and colleagues ${ }^{23}$ found single women had better mental health outcomes than married women, albeit their study was based on an elderly sample.

In relation to cohabitation and marriage, the results presented here suggest that they have different effects on men's and women's health, while the findings in the literature are mixed. Some studies find that there are no health differences between people who cohabit and those that marry. ${ }^{24}$ However, other studies have found that people who cohabit have higher levels of depression than their married counterparts. ${ }^{425} 26$ Although a number of these studies pay careful attention to potential mediators that may explain these differences, none of them explore the associations for men and women separately, and they hence do not shed light on the particular findings here, which suggest that marriage in itself may be more beneficial for women's mental health than cohabitation.

Cohabiting individuals have been described as being more receptive of divorce and selective of those less committed to their relationships. ${ }^{26}$ Brown finds that the higher rates of depression among people who cohabit can be explained by the quality of the relationship, in particular, its stability, and that the differences between people who cohabit and marry are only apparent among those in long term relationships. ${ }^{27}$ Other studies have also found differences in the health of people who cohabit are more apparent in long term relationships, where again, the explanatory factors seem to be the quality of the relationship and the extent of commitment. ${ }^{28}$

Finally, this study found that the beneficial and harmful effects of partnership change on mental health varied over time. Similarly, in the literature, negative outcomes for mental health have not always been evident immediately after partnership transitions. Psychological distress may only occur during the period surrounding a partnership split. ${ }^{7}$ For 


\section{Policy recommendations}

This is a difficult area to make policy recommendations in, and further research is required to understand some of the casual factors behind these associations. However, two policy recommendations would seem important from the results presented here.

- The United Kingdom parliament should review the law in relation to cohabitation rights. The lack of protection of the financial and property rights, and hence the security, of cohabiting couples when they separate may explain why women who cohabit have poorer mental health than women who marry.

- Local social services and non-statutory organisations supporting people during and after separation and divorce should target their support on women who have experienced multiple separations.

example, one study found that depression and anxiety differed according to the stage of divorce. Those people in happy marriages or those divorced for six to twelve months had better health than those currently separating or in the earlier stages of divorce. ${ }^{29}$ Similarly Ren found that people currently separating from their partner had higher rates of depression than those in unhappy marriages and those who had already divorced. ${ }^{4}$

There are a number of limitations to this paper that need to be borne in mind in relation to the data available and the simplicity of the analyses undertaken here.

Although the BHPS is a large and sophisticated panel study, some of the partnership categories were too small to be analysed separately and needed to be grouped. For example, while we were able to separate marriage and cohabiting for people's final partnership status (which revealed considerable gender differences), we were not able to do the same for the lifetime partnership transition variables. Similarly, people who were divorced, separated, or widowed were grouped together because of small numbers. Although studies in the literature have generally found that people who are divorced experience the most negative mental health effects, other authors have found that people who are separated to be the most unhealthy. ${ }^{23}$ There are therefore some grounds for treating separation as distinct from divorce. However, given the lifecourse perspective adopted here, the vast majority of separations converted into divorces fairly rapidly.

This paper has only considered the number and type of partnership changes that have been encountered but has not considered the characteristics of the partnerships themselves. Various studies have suggested that the quality of relationships is more important than simply being in a relationship. In this way divorce and separation may actually promote mental health in cases in which the marriage was stressful or abusive, and conversely poor marriage or cohabiting relationships could lead to poor mental health. ${ }^{40}$ For example, Aseltine and Kessler found no depressive effects of marital disruption among those who were escaping marriages with serious long term problems. ${ }^{19}$ Characteristics of the marriage itself have also been shown to be important for health, for example, companionship and equality of decision making were particularly important when women were faced with juggling multiple roles. ${ }^{31}$ At the same time, no marriage characteristics were found to be predictive of health outcomes in men, demonstrating the importance of gender differences. $^{31}$ Taking another perspective, Simon and Marcussen found that the negative effects of marital loss, and the positive effects of a marital gain, were greater for people who believed in the desirability and importance of marriage than for those who did not hold such beliefs. ${ }^{32}$

The analyses presented in this paper have demonstrated some interesting associations between partnership transitions and health. However, to keep the analyses comparatively simple there has been no attempt to explain why different partnership transitions may be associated with different levels of mental health. In future research, we plan to use multivariate techniques within the BHPS to explore these complex interrelationships, for example, the timing of transitions and the pattern of health, before and after each transition, in more detail.

\section{ACKNOWLEDGEMENTS}

The data used in this paper were made available through the ESRC Data Archive. The data were originally collected by the ESRC Research Centre on Micro-social Change at the University of Essex (now incorporated within the Institute for Social and Economic Research). ${ }^{9}$ Neither the original collectors of the data nor the Archive bear any responsibility for the analyses or interpretations presented here.

\section{Authors' affiliations}

M Willitts, M Benzeval, Department of Geography, Queen Mary, University of London, London, UK

S Stansfeld, Department of Psychiatry, Barts and the London Queen Mary School of Medicine and Dentistry, Queen Mary, University of London

Funding: this project is funded by the Medical Research Council Health Services and Public Health Research Board's Health of the Public Programme (strategic project grant number: 51878).

\section{REFERENCES}

1 Gove W. The relationship between sex roles, mental illness and marital status. Social Forces 1972;51:44.

2 Wyke S, Ford G. Competing explanations for associations between marital status and health. Soc Sci Med 1992;34:523-32.

3 Cox BD, Blaxter M, Buckle AL, et al. The health and lifestyle survey. London: Health Promotion Research Trust, 1987.

4 Ren XS. Marital status and quality of relationships: the impact on health perception. Soc Sci Med 1997:44:241-9.

5 Benzeval M. The self-reported health status of lone parents. Soc Sci Med 1998;46:1337-53.

6 Booth A, Amato P. Divorce and psychological distress. J Health Soc Behav $1991 ; 32: 396-407$

7 Hope S, Rodgers B, Power C. Marital status transitions and psychological distress: longitudinal evidence from a national population sample. Psychol Med 1999:29:381-9.

8 Richards M, Hardy R, Wadsworth M. The effect of divorce and separation on mental health in a national UK birth cohort. Psychol Med 1997;27:1121-8.

9 ESRC Research Centre on Micro-social Change. Principal investigator. British Household Panel Survey, [computer file]. Colchester: The Data Archive, University of Essex, 2001.

10 Taylor M. British household panel study user manual: Introduction, technical reports and appendices. Colchester: ESRC Research Centre on Micro-social Change, University of Essex, 1998.

11 Berthoud R. Introduction: the dynamics of social change. In: Berthoud R, Gershuny J, eds. Seven years in the lives of British families. Evidence on the dynamics of social change from the British Household Panel Survey. Bristol: The Policy Press, 2000:1-20.

12 Taylor M. Appendix: sampling characteristics, attrition and weighting. In: Buck N, Gershuny J, Rose D, et al, eds. Changing households: The British household panel survey. Colchester: ESRC Research Centre on Micro-social change, University of Essex, 1994:291-311.

13 Goldberg D, Williams P. A user's guide to the General Health Questionnaire. Windsor: NFER-Nelson, 1988.

14 Stansfeld S, Marmot M. Social class and minor psychiatric disorder in British civil servants: a validated screening survey using the General Health Questionnaire. Psychol Med 1992;22:739-49.

15 Mausner JS, Kramer S. Epidemiology an introductory text. London: WB Saunders, 1985.

16 Breslow NE, Day NE. Statistical methods in cancer research: vol 2 the design and analysis of cohort studies. Oxford: Oxford University Press, 1987:48-79.

17 Barrett A. Marital trajectories and mental health. J Health Soc Behav 2000;41:451-64.

18 Friedman HS, Tucker JS, Schwartz JE, et al. Psychosocial and behavioural predictors of longevity. Am Psychol 1995;50:69-78. 
19 Aseltine RH, Kessler RC. Marital disruption and depression in a community sample. J Health Soc Behav 1993;34:237-51.

20 Maciejewski PK, Prigerson HG, Mazure CM. Sex differences in event-related risk for major depression. Psychol Med 2001;31:593-604.

21 Kiecolt-Glaser JK, Newton TL. Marriage and health: his and hers. Psychol Bull 2001; 127:472-503

22 Bebbington P, Hurry J, Tennant CC, et al. The epidemiology of mental disorders in Camberwell. Psychol Med 1981;11:561-79.

23 Goldman N, Korenman S, Weinstein R. Marital status and health among the elderly. Soc Sci Med 1995;40:1717-30

24 Ross CE. Reconceptualizing marital status as a continuum of social attachment. Journal of Marriage and the Family 1995;57:129-40.

25 Horwitz AV, Raskin White $\mathrm{H}$. The relationship of a cohabitation and mental health: a study of a young adult cohort. Journal of Marriage and the Family 1998;60:505-14.
26 Axinn WG, Thornton A. The relationship between cohabitation and divorce: selectivity or causal influence? Demography 1992;29:357-74.

27 Brown SL. The effect of union type on psychological well-being: depression among cohabitors versus marrieds. J Health Soc Behav 2000;41:241-55.

28 Brown SL, Booth A. Cohabitation versus marriage: a comparison of relationship quality. Journal of Marriage and the Family 1996;58:668-78.

29 Hackney G, Ribordy S. An empirical investigation of emotional reactions to divorce. J Clin Psychol 1981;36:105-10.

30 Edwards AC, Nazroo JY, Brown GW. Gender differences in marital support following a shared life event. Soc Sci Med 1998;46:1077-85.

31 Hibbard J, Pope C. The quality of social roles as predictors of morbidity and mortality. Soc Sci Med 1993;36:217-25.

32 Simon RW, Marcussen K. Marital transitions, marital beliefs and mental health. J Health Soc Behav 1999;40:111-25.

\section{Clinical Evidence-Call for contributors}

Clinical Evidence is a regularly updated evidence based journal available worldwide both as a paper version and on the internet. Clinical Evidence needs to recruit a number of new contributors. Contributors are health care professionals or epidemiologists with experience in evidence based medicine and the ability to write in a concise and structured way.

\section{Currently, we are interested in finding contributors with an interest in} the following clinical areas:

Altitude sickness; Autism; Basal cell carcinoma; Breast feeding; Carbon monoxide poisoning; Cervical cancer; Cystic fibrosis; Ectopic pregnancy; Grief/bereavement; Halitosis; Hodgkins disease; Infectious mononucleosis (glandular fever); Kidney stones; Malignant melanoma (metastatic); Mesothelioma; Myeloma; Ovarian cyst; Pancreatitis (acute); Pancreatitis (chronic); Polymyalgia rheumatica; Post-partum haemorrhage; Pulmonary embolism; Recurrent miscarriage; Repetitive strain injury; Scoliosis; Seasonal affective disorder; Squint; Systemic lupus erythematosus; Testicular cancer; Varicocele; Viral meningitis; Vitiligo However, we are always looking for others, so do not let this list discourage you.

Being a contributor involves:

- Appraising the results of literature searches (performed by our Information Specialists) to identify high quality evidence for inclusion in the journal.

- Writing to a highly structured template (about 2000-3000 words), using evidence from selected studies, within 6-8 weeks of receiving the literature search results.

- Working with Clinical Evidence Editors to ensure that the text meets rigorous epidemiological and style standards.

- Updating the text every eight months to incorporate new evidence.

- Expanding the topic to include new questions once every 12-18 months.

If you would like to become a contributor for Clinical Evidence or require more information about what this involves please send your contact details and a copy of your CV, clearly stating the clinical area you are interested in, to Claire Folkes (cfolkes@bmigroup.com).

\section{Call for peer reviewers}

Clinical Evidence also needs to recruit a number of new peer reviewers specifically with an interest in the clinical areas stated above, and also others related to general practice. Peer reviewers are health care professionals or epidemiologists with experience in evidence based medicine. As a peer reviewer you would be asked for your views on the clinical relevance, validity, and accessibility of specific topics within the journal, and their usefulness to the intended audience (international generalists and health care professionals, possibly with limited statistical knowledge). Topics are usually $2000-3000$ words in length and we would ask you to review between 2-5 topics per year. The peer review process takes place throughout the year, and our turnaround time for each review is ideally 10-14 days.

If you are interested in becoming a peer reviewer for Clinical Evidence, please complete the peer review questionnaire at www.clinicalevidence.com or contact Claire Folkes(cfolkes@bmigroup.com). 